\title{
Chemical composition diversity of fucoidans isolated from three tropical brown seaweeds (Phaeophyceae) species
}

\author{
FADILAH NORLAILI LUTFIA ${ }^{1}$, ALIM ISNANSETYO ${ }^{2, \bullet}$, RATNA ASMAH SUSIDARTI ${ }^{3}$, \\ MUHAMMAD NURSID ${ }^{4}$ \\ ${ }^{1}$ Department of Biotechnology, Graduate School, Universitas Gadjah Mada. Jl. Teknika Utara, Sleman 55281, Yogyakarta, Indonesia \\ ${ }^{2}$ Department of Fisheries, Faculty of Agriculture, Universitas Gadjah Mada. Jl. Flora, Bulaksumur, Sleman 55281, Yogyakarta, Indonesia. \\ Tel./fax.: +62-274-563062, `email: isnansetyo@ugm.ac.id \\ ${ }^{3}$ Departmen of Pharmacochemistry, Faculty of Pharmacy, Universitas Gadjah Mada. Jl. Sekip Utara, Bulaksumur, Sleman 55281, Yogyakarta, Indonesia \\ ${ }^{4}$ Research and Development Center for Marine and Fisheries Product Processing and Biotechnology, Ministry of Fisheries and Marine Affair, Indonesia \\ Jl. KS Tubun Petamburan VI, Slipi, Jakarta Pusat 10260, Jakarta, Indonesia
}

Manuscript received: 2 February 2020. Revision accepted: 19 June 2020.

\begin{abstract}
Lutfia FN, Isnansetyo A, Susudarti RA, Nursid M. 2020. Chemical composition diversity of fucoidans isolated from three tropical brown seaweeds (Phaeophyceae) species. Biodiversitas 21:3170-3177. Fucoidan is a polysaccharide with high sulfate content, found in the cell walls matrix of brown seaweed. Its bioactivities vary depending on the algae species and the chemical structure. The aims of this research were to extract, purify, and characterize fucoidan from three Indonesian brown seaweed, Sargassum sp., Turbinaria sp., and Padina sp. The extraction was carried out using acid method followed by precipitation with ethanol and $\mathrm{CaCl}_{2}$, while its purification using DEAE-cellulose ion-exchange chromatography. Characterization was performed by FTIR and ${ }^{1} \mathrm{H}-\mathrm{NMR}$ spectroscopic analyses. Chemical components of fucoidan determined were total carbohydrates, sulfate residue, uronic acid residue, and monosaccharide components. The results revealed that the Turbinaria sp. produced highest yield of fucoidan (4.8\% dry matter), followed by Sargassum sp. (2.7\% dry matter) and Padina sp. (2.6\% dry matter). The carbohydrate contents of Sargassum sp., Turbinaria sp. and Padina sp. fucoidan were $64.55 \pm 0.12 \%, 67.42 \pm 0.03 \%$ and $62.90 \pm 0.04 \%$ with sulfate residues of $0.013 \% \pm 4.71$; $19.47 \pm 0.002 \%$ and $0.016 \% \pm 8.81$; and uronic acid residues of $25.19 \pm 0.03 \% ; 12.69 \pm 0.03 \%$ and $12.91 \pm 0.01 \%$, respectively. Sargassum sp., Turbinaria sp., and Padina sp. fucoidans consist of fucose and some other minor monosaccharides.
\end{abstract}

Keywords: Characterization, Padina, Sargassum, sulfated carbohydrate, Turbinaria

\section{INTRODUCTION}

Approximately 1800 species of brown seaweed (Phaeophyceae) in the world have been identified and some have been exploited as sources of functional foods, pharmaceuticals, nutraceuticals, and cosmetics (Morya et al. 2012). One of the valuable substances is fucoidan due to its multi-bioactivities. Brown seaweed group is the only algae class of Phaeophyceae which contains fucoidan as the cell wall component. Fucoidan is a type of sulfated polysaccharide consisting of sulfated L-fucose with a small portion of xylose, galactose, glucose, mannose, rhamnose and uronic acid (Thinh et al. 2013) Fucoidan have extensive bioactivities, such as antioxidants, antiinflammatory, anticoagulant, immuno-stimulatory and antitumor ( $\mathrm{Li}$ et al. 2008; Fernando et al. 2020). The properties of fucoidan bioactivity have been the subject of interest of scientists, and various food and fine chemical industries in recent years which drive increasing demand for fucoidan extracted from brown seaweed. Many articles have discussed and reviewed thoroughly the biological, pharmacological, and pharmaceutical applications of fucoidans, which have made it a hot topic in the past few decades. All of these studies tried to investigate the molecular mechanism of fucoidans in relation to their chemical structure and physicochemical properties (Zayed and Ulber 2020).

We have previously reported the anti-cancer activity of fucoidans extracted from three Indonesian Phaeophyceae species (Isnansetyo et al. 2017) and immunostimulating activity of fucoidan from tropical Phaeophyceae species (Isnansetyo et al. 2016; Setyawan et al. 2018; Purbomartono et al. 2019). As the activities highly correspond to Fucoidans from Phaeophyceae have a very complex structure with varying chemical composition within and between species. In addition, other factors affecting the chemical composition of fucoidan are growth environment, age, and collection season (Lee et al. 2006), and also geographical location (Lim et al. 2019. The differences in chemical composition of fucoidans were thought to be associated with their biological activities (Thinh et al. 2013). However, little research on the comparison of chemical characteristics of fucoidan among tropical species Phaeophyceae is found.

Diverse species of Phaeophyceae are distributed around the world, but limited species are exploited commercially for the source of fucoidan. Obviously, a lot more research needs to be done to explore the potential of Phaeophyceae as a possible source of medicinal agents especially fucoidan. In the previous study, we found that three Phaeophyceae species, Sargassum sp., Turbinaria sp. and 
Padina sp. produce fucoidan with different level of activities against colon and breast cancers (Isnansetyo et al. 2017), there is no report on the chemical diversities of fucoidan from the three brown seaweeds. In order to understand the variation of the activity, the properties of fucoidan extracted from the algae species were characterized.

\section{MATERIALS AND METHODS}

\section{Sample Collection}

Three Phaeophyceae species samples were taken at low tide conditions in the intertidal zone of coastal region of Drini, Gunung Kidul, Yogyakarta, Indonesia in May 2015. The Phaeophyceae species were placed in a cool container and then carried to the lab. The algae samples were rinsed with tap water before air drying to obtain dry biomass. The dried samples were powdered and then stored in plastic bags at $5^{\circ} \mathrm{C}$ until used. The identification of specimens and characterization of fucoidan were carried out based on previously published methods (Trono et al. 1999; Dhargalkar et al. 2014).

\section{Extraction and isolation of fucoidan}

Fifty grams of dried powdered brown seaweed was soaked in $800 \mathrm{ml}$ of $0.1 \mathrm{~N} \mathrm{HCl}$ (Mallinckrodt, Baker inc., Paris, Kentucky) at room temperature for 24 hours then filtered. The filtrate was neutralized with $\mathrm{NaOH}$ then precipitated by the addition of twice the volumes of ethanol and then allowed to stand at $5^{\circ} \mathrm{C}$ overnight. The mixture was centrifuged at 3,500 rpm for 30 minutes to remove the supernatant. The remaining sediment was dissolved in $\mathrm{pH} 2$ by adding $\mathrm{HCl}$ then added with $\mathrm{CaCl}_{2}$ to a final concentration of $4 \mathrm{M}$. This mixture was then stored at $5^{\circ} \mathrm{C}$ overnight before being centrifuged at 3,000 rpm for 15 minutes. The supernatant was collected and added with ethanol, in order to precipitate fucoidan. The mixture was centrifuged at $3,000 \mathrm{rpm}$ for 20 minutes. The crude fucoidan obtained was further purified by DEAE-cellulose column chromatography.

\section{Purification of fucoidan}

Crude fucoidan was applied to DEAE-cellulose (SigmaAldrich. Co,. Spruce St. Louis, USA) ion-exchange chromatography and eluted with distilled water followed by a linear gradient of 0.5 to $3 \mathrm{M} \mathrm{NaCl}$. Fractions of $20 \mathrm{ml}$ were collected and total carbohydrate content was determined by phenol-sulfuric acid method according (Masuko et al. 2005) using L-fucose (Nacalai Tesque, Kyoto, Japan) as a reference. Carbohydrate-containing fractions were treated with ethanol and the mixture was centrifuged at 3,000 rpm for 15 minutes to separate the supernatant. The purified fucoidan was dissolved in distilled water, dialyzed (12,300 Da molecular weight cutoff) (Sigma) for 48 hours before freeze-drying. Finally, the purified fucoidan was stored at $5^{\circ} \mathrm{C}$ for further experiments.

\section{Fucoidan characterization \\ FTIR analysis}

The infrared spectra of purified fucoidan in $\mathrm{KBr}$ pellets ( $2 \mathrm{mg}$ fucoidan in $100 \mathrm{mg} \mathrm{KBr}$ ) were recorded using a FTIR spectrometer (Perkin Elmer) at a wavenumber range of 400 to $4000 \mathrm{~cm}^{-1}$. The IR spectra of purified fucoidan were compared with that of standard fucoidan (SigmaAldrich, St. Louis, MO, USA).

\section{Determination of total carbohydrates content}

One milligram of purified fucoidan was dissolved in 1 $\mathrm{ml}$ of distilled water. Fifty microliters of solution were transferred into a microplate well containing $150 \mu \mathrm{l}$ of concentrated $\mathrm{H}_{2} \mathrm{SO}_{4}$ (Merck, KGaA, Darmstadt, Germany) then shaken for 20 minutes, followed by the addition of 30 $\mu \mathrm{l}$ of $5 \%$ phenol. The microplate was heated at $90^{\circ} \mathrm{C}$ for 5 minutes and then left at room temperature for 5 minutes. The absorbance of the solution was then measured at 490 $\mathrm{nm}$. The same experiment was done for a series of standard L-fucose (Nacalai Tesque, Kyoto, Japan) solution (100 to $1000 \mathrm{ppm}$ ) to obtain the standard curve (Masuko et al. 2005).

\section{Determination of sulfate residue \\ Preparation $\mathrm{BaCl}_{2}$-Gelatin solution}

The measurement of sulfate residue in the fucoidan was conducted using $\mathrm{BaCl}_{2}$-gelatin method (Dodgson et al. 1962) using $\mathrm{Na}_{2} \mathrm{SO}_{4}$ (Merck KGaA, Darmstadt, Germany) at concentrations of $100-1000 \mathrm{ppm}$ as a standard solution. Gelatin solution was prepared by dissolving $0.25 \mathrm{~g}$ gelatin in distilled water $\left(60^{\circ} \mathrm{C}\right)$ to a final $50.0 \mathrm{ml}$ of solution, then allowed to cool and stored at $4{ }^{\circ} \mathrm{C}$ overnight. The $\mathrm{BaCl}_{2}$ gelatin solution was prepared by dissolving $0.25 \mathrm{~g} \mathrm{BaCl}_{2}$ in gelatin solution to a final volume of $50.0 \mathrm{ml}$. $\mathrm{BaCl}_{2}$-gelatin solution was stored at $4^{\circ} \mathrm{C}$ before use for as long as a week.

\section{Measurement of sulfate residue}

One mg of fucoidan was dissolved in $1 \mathrm{ml}$ of $1 \mathrm{~N} \mathrm{HCl}$ and then heated in an oven at $105^{\circ} \mathrm{C}$ for 4 hours. Ten microliters solution was added into microplate well containing $190 \mu \mathrm{l}$ of TCA (Merck KGaA, Darmstadt, Germany) $4 \%$. The mixture was then added $50 \mu \mathrm{BaCl}_{2}$ gelatin solution and shaken for 20 minutes. The absorbance of the solution was measured with a microplate reader (HEALES, MB-580, Shenzhen, China) at $360 \mathrm{~nm}$ (Dodgson et al. 1962).

\section{Determination of Uronic Acid Residue}

The uronic acid residues were determined by a spectrophotometer (Genesys 10S UV-VIS Spectrophotometer, Thermo Scientific) using glucuronic acid (AppliChem GmbH, Darmstadt, Germany) as standard (Kurita et al. 2008). One milligram of fucoidan sample was dissolved in $1 \mathrm{ml}$ of $1 \% \mathrm{NaCl}$ then $250 \mu \mathrm{l}$ of solution was put into a test tube and then added $2 \mathrm{ml}$ of cold concentrated sulfuric acid (Merck KGaA, Darmstadt, Germany). The mixture was heated in a water bath at $100^{\circ} \mathrm{C}$ for 10 minutes then added $100 \mu \mathrm{l}$ solution of trimethyl-phenol (0.1 g trimethyl-phenol powder (TCI, Tokyo, Japan) dissolved in of glacial acetic acid (Merck 
KGaA, Darmstadt, Germany) until $100.0 \mathrm{ml}$ of solution). The solution was vortexed and allowed to stand for 10 minutes and then the absorbance was measured at $450 \mathrm{~nm}$.

\section{Determination of Monosaccharides}

The content of monosaccharides in fucoidan was determined after acid hydrolysis. Five milligrams of fucoidan standard (Sigma-Aldrich. Co,. Spruce St. Louis, USA, Product of Australia) was dissolved in $1 \mathrm{ml} \mathrm{HPLC}$ grade water then treated with $1 \mathrm{ml}$ of $4 \mathrm{M}$ trifluoroacetic acid. The solution was heated for 2 hours at $100^{\circ} \mathrm{C}$ then filtered by $0.45 \mu \mathrm{m}$ pore size filter (Merck $\mathrm{KGaA}$, Darmstadt, Germany). The filtrate was neutralized with $0.1 \mathrm{M} \mathrm{NaOH}$ and then evaporated with liquid nitrogen until the remaining volume of $0.5 \mathrm{ml}$. The content of monosaccharides of the fucoidan hydrolyzate was analyzed by High-Performance Liquid Chromatography (HPLC) (Shimadzu, SIL-10AD) using a refractive index detector (RID) equipped with a ligand-exchange column for Carbohydrate (Agilent Hi-Plex H, $7.7 \times 100 \mathrm{~mm}$ ) eluted with $0.005 \mathrm{M} \mathrm{H}_{2} \mathrm{SO}_{4}$ at a flow rate of $0.7 \mathrm{ml} / \mathrm{min}$. A sample of $20 \mu \mathrm{l}$ was injected with separation time of 30 minutes. The standard monosaccharides used were fucose (Nacalai Tesque, Kyoto, Japan), glucose (Merck KGaA, Darmstadt, Germany), galactose (Merck KGaA, Darmstadt, Germany), rhamnose (Cica Reagen, Kanto Chemical, Tokyo, Japan), mannose (Merck KGaA, Darmstadt, Germany) and xylose (Merck KGaA, Darmstadt, Germany).

\section{${ }^{1} H$-NMR Analysis}

The ${ }^{1} \mathrm{H}-\mathrm{NMR}$ spectra of fucoidan samples $(10 \mathrm{mg}$ in $600 \mu \mathrm{l}$ of $\mathrm{D}_{2} \mathrm{O}$ ) were recorded by NMR JEOL ECS 400 $\mathrm{MHz}$ and then compared with that of standard fucoidan.

\section{RESULTS AND DISCUSSION}

\section{Extraction and Purification of Fucoidan}

In this study, three species of Phaeophyceae were extracted by using acid method with different yields of fucoidan. Turbinaria sp. produced highest yields of fucoidan $(4.8 \%)$ followed by Sargassum sp. (2.7\%), and Padina sp. $(2.6 \%)$. The yields of fucoidan are various among the species of Phaeophyceae. For instance, the yields of fucoidan are $3.9 \%$ for Undaria pinnatifida (Kim et al. 2007), 2.2\% for Saccarina latissima (Bilan et al. 2010), and $1.25 \%$ for Ascophyllan nodosum (Jiang et al. 2010).

Each species of Phaeophyceae has physiological and biochemical mechanisms to produce different metabolites. Number of metabolites produced is also directly influenced by the nutrients contents in the environment that also affect the yield of fucoidan in brown seaweed. Besides the species, other factors that affect the yield of fucoidan are time of sampling, the age of the sample and extraction methods (Lee et al. 2006)

Fucoidans isolated from Sargassum sp., Turbinaria sp., and Padina sp. were confirmed with a standard fucoidan based on their FTIR spectra (Figure 1). The overall FTIR spectra of those fucoidans exhibit similar absorption pattern (Isnansetyo et al. 2016; Isnansetyo et al. 2017). The notable difference is the appearance of absorption band at $1733 \mathrm{~cm}^{-1}$ in the FTIR spectrum of standard fucoidan indicated the presence of carbonyl group.

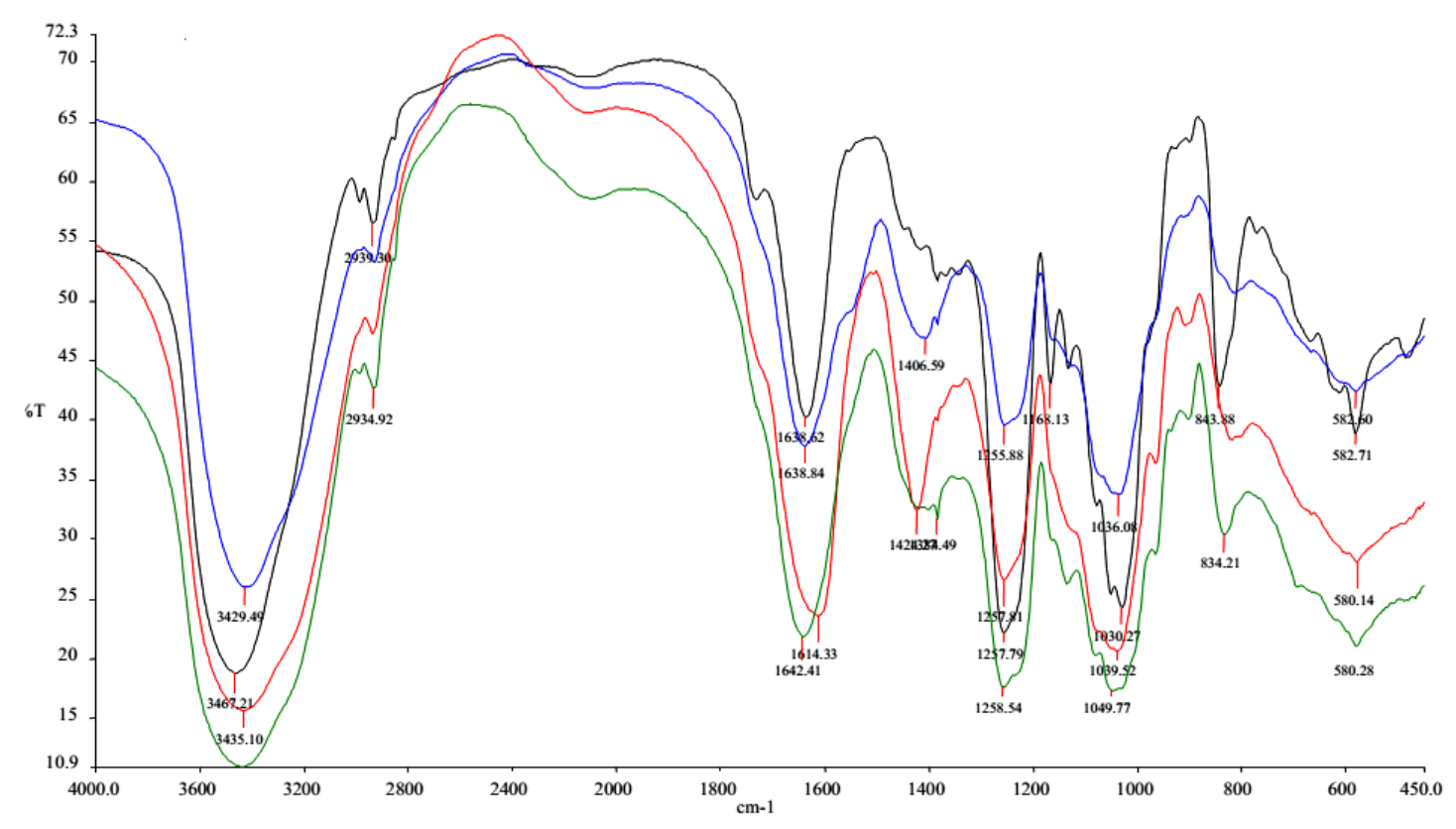

Figure 1. The Overlay FTIR spectra of Sargassum sp. (red), Turbinaria sp. (green), Padina sp. (blue) fucoidans and a commercial fucoidan as standard (black) 
Purification results by using DEAE-cellulose ionexchange chromatography revealed that the purification process yielded brown powder high purity fucoidan. This result was confirmed by HPLC analyses indicating Sargassum fucoidan was eluted as a single peak at 6.845; sp., Turbinaria sp., Padina sp. fucoidans, and also a commercial 6.772; 6.742 and 6.676 minutes of retention times, respectively (Isnansetyo et al. 2017). The fucoidan of each species of brown seaweed was then characterized for their total carbohydrate content, sulfate and uronic acid residues, and monosaccharides components compared to standard fucoidan.

\section{Characterization of fucoidan}

Total carbohydrate content

The total carbohydrate contents of Sargassum sp., Turbinaria sp., Padina sp. fucoidans were higher than that of a commercial fucoidan as shown in Table 1. The highest carbohydrate content $(67.42 \%)$ was obtained from Turbinaria sp., followed by Sargassum sp. (64.55\%) and Padina sp. (62.90\%).

Fucoidan in Phaeophyceae is heterogeneous, and composed of various units of carbohydrates and noncarbohydrates (sulfate and acetyl) (Cumashi et al. 2007). Previous studies reported that the carbohydrate content in fucoidan of some Phaeophyceae species varies, for example, $52.34 \%$ in sporophylls of Undaria pinnatifida (Kim et al. 2007), 69.0\% in Cladosiphon okamuranus (Tako et al. 2000) and $49.2 \%$ in Fucus evanescens (Men'shova et al. 2013).

\section{Sulfate residue}

Fucoidans are polysaccharides having ester sulfate groups as one of the main constituents. The concentrations of sulfate residues of fucoidan extracted from three species of Phaeophyceae and standard fucoidan varied (Table 2) and the highest concentrations were found in the fucoidan from Turbinaria sp. (19.47\%). Fucoidan of Padina sp. and Sargassum sp. contained $8.82 \%$ and $4.71 \%$ sulfate residue, respectively, and were lower than that in the standard fucoidan $(14.4 \%)$.

The main skeleton of fucoidan consists of a straightchain or sometimes branched fucose, in which the sulfate group is attached to the C-2, C-3 or C-4 of fucose. Sulfate group is essential for the bioactivity of fucoidan (Isnansetyo et al. 2017). Sulfate content in fucoidan from Phaeophyceae species varies greatly. This is due to the different biochemical and physiological mechanisms in the absorption of nutrients in the environment. Based on the sulfate content, fucoidan from Turbinaria sp. is expected to be more active than the other two species studied as well as the fucoidan standard, as it contains higher sulfate content. Fucoidan from Turbinaria sp. obtained from Tamilnadu, India contains $38 \pm 0.42 \%$ of residual sulfate (Marudhupandi et al. 2014). The differences in growth environment and sample age greatly affect the content of sulfate in fucoidan (Lee et al. 2006).

\section{Uronic Acid Residue}

Uronic acids are sugars in which the terminal carbon's hydroxyl group has been oxidized to a carboxylic acid.
Uronic acid is found in fucoidan with different concentrations that might be influenced by species of algae. Uronic acid content in fucoidan of three Phaeophyceae species studied ranged from 12.69 to $25.19 \%$ (Table 3). The results showed the highest uronic acid content (25.19 \pm 0.03 ) was obtained in fucoidan from Sargassum sp. The lower contents were found in fucoidan from Turbinaria sp. (12.69 \pm 0.03$)$, Padina sp. (12.91 \pm 0.01$)$, and standard fucoidan $(14.31 \pm 0.01)$. Several studies reported that the uronic acid content varied in fucoidan. For instance, fucoidan from Undaria pinnatifida and Saccharina latissima contain uronic acid of 26.2\% (Kim et al. 2007) and $23.3 \%$ (Bilan et al. 2010), respectively.

\section{Monosaccharides component}

The content of specific monosaccharides of fucoidan was determined using HPLC after TFA hydrolysis. Standard monosaccharides (fucose, rhamnose, xylose, mannose, galactose, and glucose) individually appear at retention times of $9.760 ; 11.585 ; 10.726 ; 10.346 ; 10.358$; 10.298; and 9.760 minutes, respectively (Table 4). Glucuronic acid appears at 8.491 minutes. The retention times of xylose, mannose, galactose are very close, so they appeared as a single peak at 10.342 minutes when analyzed together (Figure 2). This raises a problem to detect the existence of these three monosaccharides independently in the fucoidan. Chromatogram of each sample of hydrolyzed fucoidan is shown in Figure 3.

Table 1. Total carbohydrate content of fucoidans from three Phaeophyceae species and a commercial fucoidan

\begin{tabular}{lc}
\hline \multicolumn{1}{c}{ Brown seaweed species } & $\begin{array}{c}\text { Total carbohydrate } \\
\text { of fucoidan }(\boldsymbol{\%})\end{array}$ \\
\hline Sargassum sp. & $64.55 \pm 0.12$ \\
Turbinaria sp. & $67.42 \pm 0.03$ \\
Padina sp. & $62.90 \pm 0.04$ \\
A commercial fucoidan (standard) & $62.42 \pm 0.05$ \\
\hline
\end{tabular}

Table 2. Sulfate residue of fucoidans from three Phaeophyceae species and a commercial fucoidan

\begin{tabular}{lc}
\hline \multicolumn{1}{c}{ Brown seaweed species } & $\begin{array}{c}\text { Sulfate content } \\
(\boldsymbol{\%})\end{array}$ \\
\hline Sargassum sp. & $4.71 \pm 0.013$ \\
Turbinaria sp. & $19.47 \pm 0.002$ \\
Padina sp. & $8.82 \pm 0.016$ \\
A commercial fucoidan (standard) & $14.4 \pm 0.015$ \\
\hline
\end{tabular}

Tabel 3. Uronic acid residue of fucoidans from three Phaeophyceae species and a commercial fucoidan

\begin{tabular}{lc}
\hline Brown seaweed species & $\begin{array}{c}\text { Uronic acid residue } \\
(\boldsymbol{\%})\end{array}$ \\
\hline Sargassum sp. & $25.19 \pm 0.03$ \\
Turbinaria sp. & $12.69 \pm 0.03$ \\
Padina sp. & $12.91 \pm 0.01$ \\
A commercial fucoidan (standard) & $14.31 \pm 0.01$ \\
\hline
\end{tabular}


Table 4. Retention time $(\mathrm{min})$ of monosaccharides of fucoidan from three Phaeophyceae species and a commercial fucoidan monosaccharides

\begin{tabular}{|c|c|c|c|c|c|}
\hline \multicolumn{4}{|c|}{ Retention time of fucoidan samples } & \multirow{2}{*}{$\begin{array}{l}\text { Retention time of } \\
\text { standard } \\
\text { monosaccharides }\end{array}$} & \multirow[b]{2}{*}{ Monosaccharides } \\
\hline Sargassum sp. & Turbinaria sp. & Padina sp. & $\begin{array}{l}\text { A commercial } \\
\text { fucoidan }\end{array}$ & & \\
\hline & 9.737 & & & 9.758 & Glucose \\
\hline 10.361 & 10.342 & 10.368 & 10.371 & 10.342 & Mannose/ xylose/galactose \\
\hline 11.598 & 11.593 & 11.614 & 11.632 & 11.583 & Fucose \\
\hline
\end{tabular}

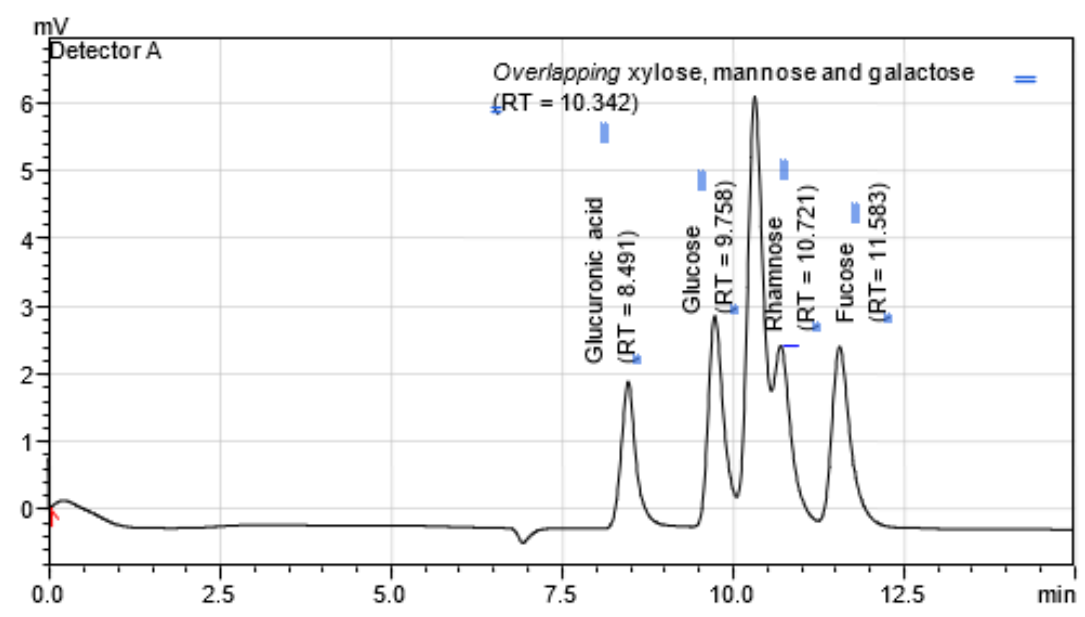

Figure 2. HPLC chromatogram of fucose, rhamnose, xylose, mannose, galactose, glucose and glucuronic acid mixture as standard monosaccharides
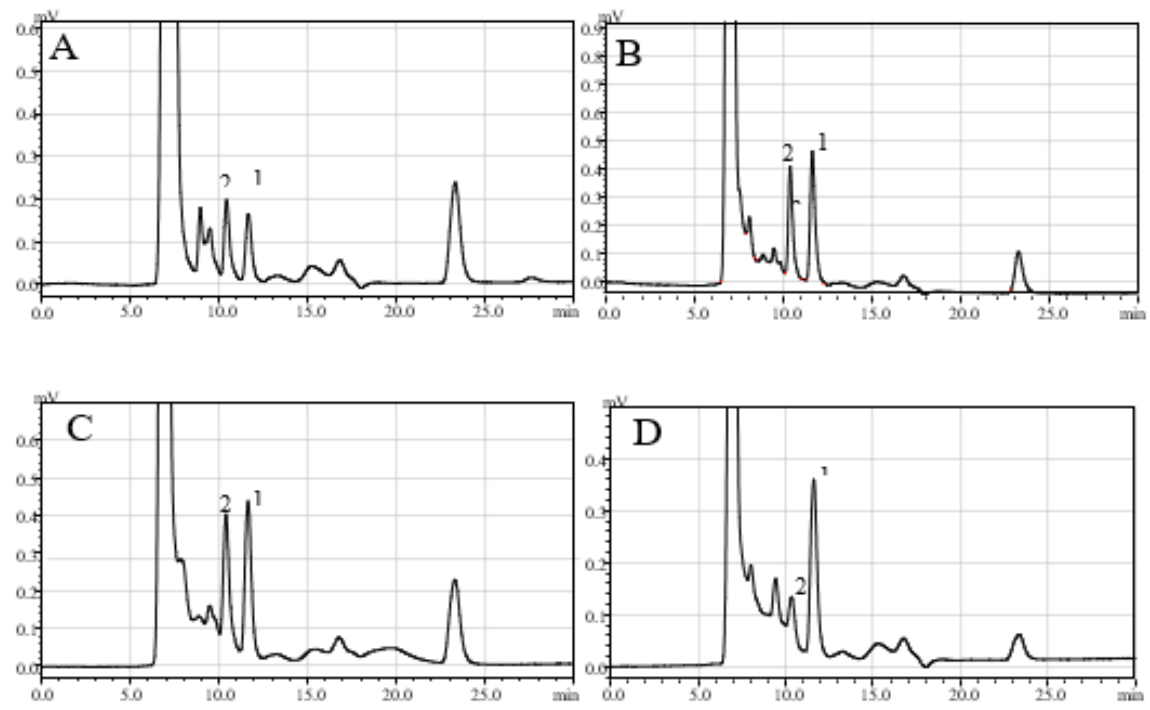

Figure 3. HPLC chromatograms of hydrolyzed Sargassum sp. (A), Turbinaria sp. (B), Padina sp. (C) fucoidans, and a commercial fucoidan (D). 1. Fucose, 2. Mannose/xylose/galactose, 3. Glucose

\section{FTIR analysis}

The FTIR spectra are particularly informative with broad strong bands around $3435 \mathrm{~cm}^{-1}$ attributed to $\mathrm{O}-\mathrm{H}$ stretching of hydrogen-bonded hydroxyl groups ( $\mathrm{Na}$ et al. 2010) common to all fucoidan. The weak band around $2935 \mathrm{~cm}^{-1}$ represents $\mathrm{C}-\mathrm{H}$ stretching vibration of pyranose ring (Marudhupandi et al. 2014). Two bands around 1630 $\mathrm{cm}^{-1}$ and $1420 \mathrm{~cm}^{-1}$ characteristic for asymmetrical and symmetrical stretching vibration of carboxylate $\left(\mathrm{RCOO}^{-}\right)$, respectively indicate the existence of uronic acid residue ( $\mathrm{Na}$ et al. 2010). The existence of sulfate ester group as a characteristic component of fucoidan was represented by strong bands around $1255 \mathrm{~cm}^{-1}$ attributed to $\mathrm{S}=\mathrm{O}$ stretching vibration. Absorption band around $1035 \mathrm{~cm}^{-1}$ indicating C- 
$\mathrm{O}$ and $\mathrm{C}-\mathrm{C}$ bonds of pyranose ring and glycoside $\mathrm{C}-\mathrm{O}-\mathrm{C}$ bond (Marudhupandi et al. 2014), whereas in the region of $800 \mathrm{~cm}^{-1}$ shows the bond C-O-S (Synytsya et al. 2010). The vibrational band at $1733 \mathrm{~cm}^{-1}$ in the FTIR spectrum of standard fucoidan indicates the presence of $\mathrm{C}=\mathrm{O}$ group. This confirmed the standard fucoidan contains acetylated sugar. In contrast, the fucoidans obtained from three algae species in the present study did not contain acetylated sugars. In fact, only a small fraction of such fucoidans are present in brown seaweed, such as Undaria pinnatifida (Synytsya et al. 2010) and Costaria costata (Ermakova et al. 2011). The largest components of fucoidan, in general, are L-fucose and sulfate (Senthilkumar et al. 2013). The FTIR spectral data of fucoidan from three species of Phaeophyceae and a commercial fucoidan is shown in Table 5.

Table 5. FTIR Spectral data of fucoidans from three Phaeophyceae species and a commercial fucoidan (Pretsch et al. 2009)

\begin{tabular}{|c|c|c|c|c|c|}
\hline $\begin{array}{l}\text { Sargassum sp. } \\
\left(\mathrm{cm}^{-1}\right)\end{array}$ & $\begin{array}{l}\text { Turbinaria sp. } \\
\left(\mathrm{cm}^{-1}\right)\end{array}$ & $\begin{array}{l}\text { Padina sp. } \\
\left(\mathrm{cm}^{-1}\right)\end{array}$ & $\begin{array}{l}\text { A commercial } \\
\text { fucoidan }\left(\mathrm{cm}^{-1}\right)\end{array}$ & $\begin{array}{c}\text { General spectra } \\
\left(\mathrm{cm}^{-1}\right)\end{array}$ & Functional groups ${ }^{*}$ \\
\hline 3,432 & 3,435 & 3,421 & 3,467 & $3,200-3,500$ & $\mathrm{O}-\mathrm{H}$ \\
\hline \multirow[t]{2}{*}{2,938} & 2,942 & 2,935 & 2,939 & $2,700-3,000$ & C-H \\
\hline & & & 1,733 & $1,350-1,800$ & $\mathrm{C}=\mathrm{O}$ \\
\hline 1,611 & 1,639 & 1,630 & 1,639 & $1,550-1,610$ & asym. - $\mathrm{COO}^{-}$ \\
\hline 1,419 & 1,420 & 1,420 & 1,417 & $1,300-1,420$ & sym. - $\mathrm{COO}^{-}$ \\
\hline 1,256 & 1,255 & 1,255 & 1,258 & $1,000-1,300$ & $\mathrm{~S}=\mathrm{O}$ \\
\hline 817 & 835 & 800 & 844 & $700-850$ & $\mathrm{C}-\mathrm{O}-\mathrm{S}$ \\
\hline
\end{tabular}

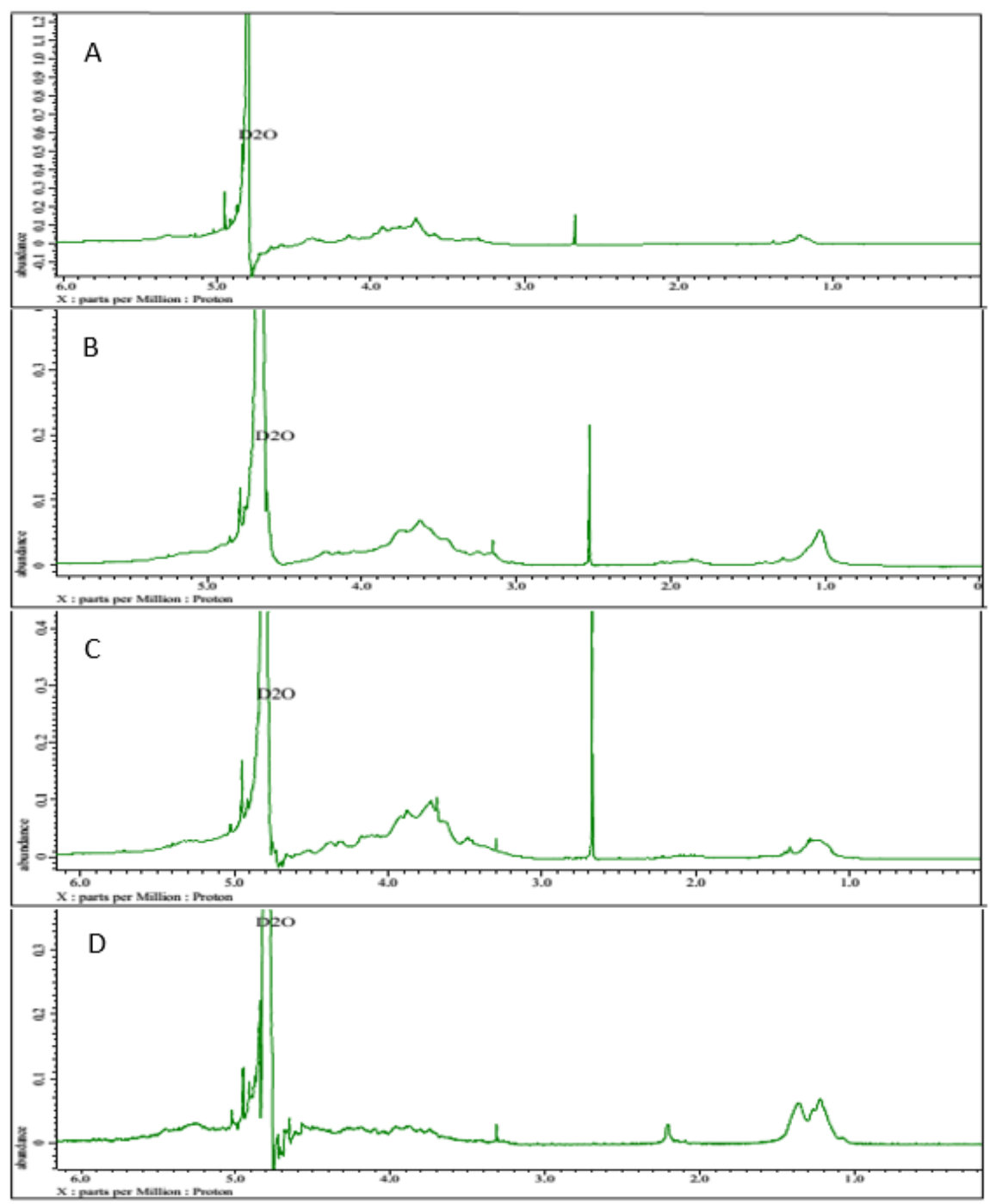

Figure 4. ${ }^{1} \mathrm{H}-\mathrm{NMR}$ spectra of Sargassum sp. (A), Turbinaria sp. (B), Padina sp. (C) fucoidans and a commercil fucoidan (D) 


\section{${ }^{1}$ H-NMR Analysis}

The ${ }^{1} \mathrm{H}-\mathrm{NMR}$ spectra of Sargassum sp., Turbinaria sp., Padina sp. fucoidans, and a commercial fucoidan showed in Figure 4. The existence of fucose is clearly confirmed by the appearance of a signal at 1.1-1.5 ppm. In the ${ }^{1} \mathrm{H}-\mathrm{NMR}$ spectrum of standard fucoidan, this signal appears as a doublet and was assigned as the resonance of the methyl protons (C-6) coupled to the neighboring methine proton (C-5) (Tako et al. 2000). Signal at 3-5 ppm was assigned as the resonances of hydroxyl groups of the monosaccharides of fucoidans. The anomeric protons of sugars were represented by the downfield signals at 4.9 to $5.6 \mathrm{ppm}$ (Marudhupandi et al. 2014). The signal at $2.8 \mathrm{ppm}$ in the ${ }^{1} \mathrm{H}-\mathrm{NMR}$ of fucoidans from studied brown seaweed species indicated the presence of amino sugars, wherein one hydroxyl group of the monosaccharide is replaced by the amino group. This signal does not seem to be not found in the standard fucoidan spectrum. The amino sugars have been found in fucoidan from $V$. vesiculosus (Nishino et al. 1994) and Saccharina japonica (Saravana et al. 2016). The signal at $2.1 \mathrm{ppm}$ in the spectrum of standard fucoidan supported the existence of the acetyl group (Tako et al. 2000).

In conclusion, extraction of brown seaweed species, Sargassum sp., Turbinaria sp., and Padina sp. resulted in the isolation of pure fucoidan with a yield of $2.7 \%, 4.8 \%$ and $2.6 \%$ of the dry matter, respectively. This study confirmed the variation of the chemical characteristics of the fucoidans present in the three brown seaweed species from Indonesia.

\section{ACKNOWLEDGEMENTS}

We wish to express sincere thanks to the Ministry of Research, Technology, and Higher Education, Republic of Indonesia for providing a research grant under the Hibah Kompetensi (HIKOM) Program (Contract number 200/LPPM/2015).

\section{REFERENCES}

Bilan MI, Grachev AA, Shashkov AS, Kelly M, Sanderson CJ, Nifantiev NE, Usov AI. 2010. Further studies on the composition and structure of a fucoidan preparation from the brown alga Saccharina latissima. Carbohydrate Research 345 (14): 2038-2047. DOI: 10.1016/j.carres.2010.07.009.

Cumashi A, Ushakova NA, Preobrazhenskaya ME, D' Incecco A, Piccoli A, Totani L, Tinari N, Morozevich GE, Berman AE, Bilan MI, Usov AI, Ustyuzhanina NE, Grachev AA, Sanderson CJ, Kelly M, Rabinovich GA, Iacobelli S, Nifantiev NE. 2007. A comparative study of the anti-inflammatory, anticoagulant, antiangiogenic, and antiadhesive activities of nine different fucoidans from brown seaweeds. Glycobiology $17 \quad$ (5): 541-542. DOI: 10.1093/glycob/cwm014.

Dhargalkar VK. 2014. Uses of seaweeds in the Indian diet for sustenance and well-being. Sci Cult 80: 192-202.

Dodgson KS, Price RG. 1962. A note on the determination of the ester sulphate content of sulphated polysaccharides. Biochemistry. 84: 106110. DOI: $10.1042 / \mathrm{bj0840106.}$

Ermakova S, Sokolova R, Kim SM, Um B, Isakov V, Ziyagintseva T. 2011. Fucoidan from brown seaweeds Sargassum honery, Eclonia cava, Costaria costata: Structural characteristic and anticancer activity. Appl Biochem Biotechnol 164: 841-850. DOI: 10.1007/s 12010-011-9178-2.

Fernando IPS, Sanjeewa KKA, Lee HG, Kim HS, Vaas APJP, Silva HICD, Nanayakkara CN, Abeytunga DTU, Lee DS, Lee JS, Jeon YJ. 2020. Fucoidan purified from Sargassum polycystum induces apoptosis through mitochondria-mediated pathway in HL-60 and MCF-7 Cells. Mar Drugs 18: 196. DOI: 10.3390/md18040196.

Isnansetyo A, Fikriyah A, Kasanah N, Murwantoko. 2016. Non-specific immune potentiating activity of fucoidan from a tropical brown algae (Phaeophyceae), Sargassum cristaefolium in tilapia (Oreochromis niloticus). Aquacult Intl 24: 465-477. DOI: 10.1007/s10499-0159938-z.

Isnansetyo A, Lutfia FNN, Nursid M, Trijoko, Sisidarti RA. 2017. Cytotoxicity of fucoidan from three tropical brown algae against breast and colon cancer cell lines. Pharmacogn J 9: 14-20. DOI: 10.5530/pj.2017.1.3.

Jiang, Zedong, Okimura T, Yokose T, Yamasaki Y, Yamaguchi K, Oda T. 2010. Effect of sulfated fucan, ascophyllan, from the brown alga Ascophyllum nodosum on various cell lines: A comparative study on ascophyllan and fucoidan. J Biosci Bioeng 110: 113-117. DOI: 10.1016/j.jbiosc.2010.01.007.

Kim WJ, Kim HG, Oh HR, Lee KB, Lee YK, Park YI. 2007. Purification and anticoagulant activity of a fucoidan from Korean Undaria $\begin{array}{llll}\text { pinnatifida } & \text { sporophyll. Algae 22: 247-252. DOI: }\end{array}$ 10.4490/algae.2007.22.3.247.

Koo JG. Jo KS, Do JR, Woo SJ. 1995. Isolation and purification of fucoidan from Laminaria religiosa and Undaria pinnatifida in Korea. J Korean Fish Soc. 28: 227-236.

Kurita O, Fujiwara T, Yamazaki E. 2008. Characterization of the pectin extracted from citrus peel in the presence of citric acid. Carbohydrate Polymers 74: 725-730. DOI: 10.1016/j.carbpol.2008.04.033.

Lee YK, Lim DJ. Lee YH, Park, YI. 2006. Variation in fucoidan contents and monosaccharide compositions of Korean Undaria pinnatifida (Harvey) Suringar (Phaeophyta). Algae 21: 157-160. DOI: 10.1007/0387-26336-5_1137.

Li B, Lu F, Wei F, Zhao R. 2008. Fucoidan: Structure and bioactivity. Molecules 13: 1671-1695. DOI: 10.3390/molecules13081671.

Lim SJ, Aida WMW, Schiehser S, Rosenau T, Böhmdorfer S. 2019. Structural elucidation of fucoidan from Cladosiphon okamuranus (Okinawa mozuku). Food Chemistry 272: 222-226. DOI: 10.1016/j.foodchem.2018.08.034.

Marudhupandi T, Kumar T, Lakshmanasenthil S, Suja G, Vinothkumar T. 2014. In-vitro anticancer activity of fucoidan from Turbinaria sp. against A549 cell lines. Intl J Biol Macromol 72: 919-923. DOI: 10.1016/j.ijbiomac.2014.10.005.

Masuko T, Minami A, Iwasaki N, Majima T, Nishimura S, Lee Y. 2005. Carbohydrate analysis by a phenol sulfuric acid method in microplate. Anal Biochem 339: 69-72. DOI: 10.1016/j.ab.2004.12.001

Men'shova RV, Lepeshkin FD, Ermakova SP, Pokrovskii OI, Zvyagintseva TN. 2013. Effect of pretreatment condition of brown algae by supercritical fluids on yield and structural characteristics of fucoidans. Chem Natl Comp 48. DOI: 10.1007/s10600-013-0429-z.

Morya VK, Kim J, Kim EK. 2012. Algal fucoidan: Structural and sizedependent bioactivities and their perspectives. Appl Microbiol Biotechnol 93: 71-82. DOI: 10.1007/s00253-011-3666-8.

Na Ye Seul, Kim JW, Kim S, Park J, Lee S, Kim S, Synytsya A, Park Y. 2010. Purification, characterization and immunostimulating activity of water-soluble polysaccharides isolated from Capsosiphon fulvescens. Intl Immunopharmacol 10: 364-370. DOI: 10.1016/j.intimp.2009.12.011.

Nishino T, Nishioka C, Ura H, Nagumo T. 1994.Isolation and partial characterization of a novel amino sugar-containing fucan sulfate from commercial Fucus vesiculosus fucoidan. Carbohydrate Res 255: $213-$ 24.

Pretsch E, Bulhman P, Badertscher M. 2009. Structure determination of organic compounds, tables of spectral data. $4^{\text {th }}$ edition. Springer. Berlin.

Purbomartono C, Isnansetyo A, Murwantoko, Triyanto. 2019. Dietary fucoidan from Padina boergesenii to enhance non-specific immune of catfish (Clarias sp.). J Biol Sci 19: 173-18. DOI: 10.3923/jbs.2019.173.180

Saravana PS, Yeon-Jin Choa, Park Y-B, Woo H-C, Chun B-S. 2016. Structural, antioxidant, and emulsifying activities of fucoidan from 
Saccharina japonica using pressurized liquid extraction Carbohydrate Polymers 153: 518-525.

Senthilkumar K, Manivasagan P, Venkatesan J, Kim SK. 2013. Brown seaweed fucoidan: Biological activity and apoptosis, growth signaling mechanism in cancer. Intl J Biol Macromol 60: 366-374. DOI: 10.1016/j.ijbiomac.2013.06.030

Setyawan A, Isnansetyo A, Murwantoko, Indarjulianto S, Handayani CR 2018. Comparative immune response of dietary fucoidan from three Indonesian brown algae in white shrimp Litopenaeus vannamei. AACL Bioflux 11 (6): 1707-1723.

Synytsya Andriy, Kim WJ, Kim SM, Pohl R, Synytsya Alla, Kvasnicka F, Copikova J, Park Y. 2010. Structure and antitumor activity of fucoidan isolated from sporophyll of Korean brown seaweeds Undaria pinnatifida. Carbohydrate Polym 81: 41-48. DOI: 10.1016/j.carbpol.2010.01.052
Tako M, Yoza E \& Tohma S. 2000. Chemical characterization of acetyl fucoidan and alginate from commercially cultured Cladosiphon okamuranus. Botanica Marina 43: 393-398. DOI: 10.1515/BOT.2000.040

Thinh PD, Menshova RV, Ermakova SP, Anastyuk SD, Ly BM \& Zvyagintseva TN. 2013. Structural characteristics and anticancer activity of fucoidan from the brown alga Sargassum mcclurei. Mar Drugs 11: 1456-1476. DOI: 10.3390/md11051456

Trono GC. 1999. Diversity of the seaweed flora of the Philippines and its utilization. Hydrobiologia 398/399: 1-6. DOI: 10.1023/A: 1017097226330.

Zayed A, Ulber R. 2020. Fucoidans: Downstream processes and recent applications. Mar Drugs 18: 170. DOI: 10.3390/md18030170. 